\title{
Self-nanoemulsifying drug delivery systems (SNEDDS): an advancement technology for oral drug delivery
}

Boontida Morakul*

Department of Pharmacy, Faculty of Pharmacy, Mahidol University, Bangkok, Thailand

*Corresponding author:

boontida.mor@mahidol.edu

\section{KEYWORDS:}

Self-nanoemulsifying drug delivery systems; SNEDDS; Oral delivery; Nanoemulsions; Poor bioavailability https://www.pharmacy.mahidol.ac.th/journal/ (c) Faculty of Pharmacy, Mahidol University (Thailand) 2020

\begin{abstract}
Nanotechnology is strongly accepted as the crucial approach in drug delivery that can influence the therapeutic performance of hydrophobic drugs. Self-nanoemulsifying drug delivery systems (SNEDDS) are one of the proven methods that can increase solubility and bioavailability of poorly water soluble drugs. SNEDDS are anhydrous homogenous liquid mixtures consisting of oil, surfactant, co-surfactant, and drugs, which spontaneously form o/w nanoemulsions when diluted with water under gentle agitation. SNEDDS provide several potential effects on oral drug delivery. This article presents an overview of SNEDDS along with their basics; such as, composition, preparation, characterization, potential effects associated with oral delivery, applications, commercially available products, advanced technology associated with SNEDDS, and trending.
\end{abstract}

\section{INTRODUCTION}

Oral administration is the most convenient and preferable way for drug delivery owing to the high degree of patient compliance. However, over $50 \%$ of drugs delivered by oral route have limited therapeutic efficacy due to their poor water solubility ${ }^{1}$. The conventional techniques including salt formation, micronization and solubilization using cosolvents, using of permeation enhancers, and complexation; such as, cyclodextrin have been employed to improve oral bioavailability. Nevertheless, these techniques have shown limited utility and required a specific drug candidate. In response to this lack in these procedures, nanotechnology has dramatically generated much interest in drug delivery research over the past few decades. The application of nanotechnology has been recognized in the provision of many benefits of drugs including enhancing the solubility of hydrophobic drugs, increasing the permeability or transport of poorly permeable drugs, improving drug stability, controlling drug distribution and disposition in the body, and targeting drug delivery to the site of action. Furthermore, several nanoparticle approaches have been developed; for example, microemulsions, nanoemulsions, solid lipid nanoparticles (SLN), nanostructured lipid carriers (NLC), polymeric micelles, polymeric nanoparticles, and inorganic nanocarriers. Moreover, 
lipid-based drug delivery systems; such as, nanoemulsions have shown the successful potential in enhancing the solubility of poorly water soluble drugs, which have been categorized as drugs in the Biopharmaceutical Classification System (BCS) classes II and IV ${ }^{2}$. The lipid-based drug delivery systems can be modified by changing their components and concentrations to make them more suitable for both hydrophilic and hydrophobic actives $^{3}$. They have the mechanism to enhance drug bioavailability by extending the drug retention time in the stomach, changing in the biophysical barrier $^{4,5}$, improving drug solubilization ${ }^{6}$, decreasing drug metabolism ${ }^{7,8}$, stimulating lymphatic transport ${ }^{9}$, and having less toxicity in vivo ${ }^{10,11}$. Nanoemulsions are the most prominent lipid-based drug delivery systems as colloidal dispersions. They are optically isotropic, transparent, thermodynamically unstable, and kinetically stable systems of oil, surfactant, and water with a nanoscopic droplet size. The ability of nanoemulsions to improve the oral bioavailability of poorly water soluble drugs has been recognized for many decades ${ }^{12}$. However, the use of nanoemulsions in oral delivery was limited due to some drawbacks; such as, poor palatability according to their lipidic composition. Moreover, nanoemulsions are usually consumed in a large volume to achieve the therapeutic concentration of the drugs which might limit the patient compliance. Additionally, the high water content of nanoemulsions results in the inability to be delivered through soft gelatin, hard gelatin, and HPMC capsules. The water content in nanoemulsions would promote hydrolysis and precipitation of drugs during storage, which would affect their utility in oral delivery ${ }^{13}$. To solve the limitation of nanoemulsions, the approach of spontaneous self-nanoemulsification has been developed for oral drug delivery.

\section{Self-nanoemulsifying drug delivery systems (SNEDDS)}

Self-nanoemulsifying drug delivery systems (SNEDDS) are nanoemulsion preconcentrates or an anhydrous form of nanoemulsions. The systems are anhydrous isotropic mixtures of oil, surfactant, active pharmaceutical ingredient, and hydrophilic co-surfactant or solubilizer ${ }^{14}$. Upon introduction into the aqueous phase followed by gentle agitation with gastric motility, the $\mathrm{o} / \mathrm{w}$ nanoemulsions are rapidly and spontaneously formed with globules ranging in size from a few nanometers to less than $200 \mathrm{~nm}^{15}$. The fine droplets of drug dissolved in the oil phase produce the enhanced interfacial surface area for dispersion into a gastrointestinal fluid. The increment in the interfacial surface area leads to an increase in drug solubilization and permeation $^{16,17}$. The nanosized SNEDDS could achieve rapid digestion and drug absorption in the gastrointestinal tract. SNEDDS can bypass the simple rate-limiting step of dissolution because the drug would be pre-dissolved. Therefore, a rapid onset of action could be achieved ${ }^{17}$. The lipid carrier of the SNEDDS would lead to an increment in the lymphatic uptake of a highly lipophilic drug and the first pass metabolism could also be reduced ${ }^{18}$. The intestinal lymphatic system is a physiological pathway for the absorption of dietary lipid digestion products; such as, long chain fatty acids, triglycerides, and cholesterol esters. In the enterocytes, long chain fatty acid and monoglyceride are esterified into triglyceride. Before the triglycerides leave the enterocytes, they are incorporated into chylomicrons. The large size of the chylomicrons are unable to pass through the blood capillaries, but they instead enter the lymphatic capillaries, which can bypass the hepatic first passage. This hypothesis has been utilized to explain the absorption of lipophilic drugs. They can associate with the triglyceride of the chylomicrons in the enterocytes and pass through the systemic circulation via the lymphatic route. The lipid-based delivery system including the SNEDDS can increase lymphatic drug transport. The oil phase used in the SNEDDS formulation is a significantly important component. Not only can it facilitate the solubilization of a lipophilic compound, but can also promote the lymphatic transport of lipophilic drugs that circumvent the hepatic portal vein route. Consequently, the opportunity for hepatic first pass metabolism would be reduced ${ }^{19}$. Additionally, the ingestion of fatty food may help in the absorption of the SNEDDS resulting in the elevation of the bioavailability ${ }^{19}$. In comparison to the conventional nanoemulsions, the SNEDDS offer improved advantages such as:

- The formulation of the SNEDDS do not contain water; therefore, the chemical and physical stability should be improved during long-term storage. 
- SNEDDS are the aqueous-free formulation, which are possible to be loaded into single unit dosage forms; such as, soft/hard gelatin or HPMC capsules. SNEDDS can be administered in dosages ranging from less than $25 \mathrm{mg}$ to greater than $2 \mathrm{~g}^{20}$. These can provide commercial viability and patient compliance.

- The palatability issue can be discarded by loading the SNEDDS into capsules.

- SNEDDS are feasible to manufacture and can be scaled up ${ }^{18,21,22}$.

\section{Mechanism of self-emulsification}

According to Reiss ${ }^{23}$, self-emulsification occurs when the entropy change that favors dispersion is greater than the energy required to increase the surface area of the dispersion. The free energy of the conventional emulsion is a direct function of the energy required to create a new surface between the oil and water phases. This can be described in Equation 1.

$$
\Delta G=\Sigma N \pi r 2 \sigma
$$

Where, $\Delta \mathrm{G}$ is the free energy, $\mathrm{N}$ is the number of droplets of the radius $r$, and $\sigma$ represents the interfacial energy. In case of the self-emulsifying systems, the energy required to form the emulsion is very low; therefore, the emulsification process can occur spontaneously. According to Wakerly et al. ${ }^{24}$, the addition of a binary mixture (oil/nonionic surfactant) to water results in an interface formation between the oil and aqueous phases, followed by the solubilization of water within the oil phase owing to the aqueous penetration through the interface. This process would occur until the solubilization limit is close to the interface.

\section{Composition of the SNEDDS formulation}

During the preparation of the SNEDDS, the following components are involved and should be taken into consideration.

\subsection{Oil phase}

The oil phase is one of the most important compositions in the SNEDDS formulation. It has the function to solubilize the lipophilic drug, facilitate self-emulsification, and increase the fraction of lipophilic drug transport through the intestinal lymphatic system. Physicochemical properties of oil including the molecular volume, polarity, and viscosity potentially govern the spontaneity of the nanoemulsification process, droplet size of the nanoemulsions, drug solubility, and biological fate of the nanoemulsions and $\operatorname{drug}^{25-27}$. To achieve the maximum drug loading, the selected oil phase should have the maximum drug solubilizing potential. Simultaneously, it should provide the small droplet size of the nanoemulsions. According to Sadurni et al. ${ }^{28}$, the lipophilicity of the oil and concentration of the oily phase in the SNEDDS are directly proportional to the nanoemulsion size. The oils with a highly long-chain hydrocarbon; such as, soybean oil and long-chain triglycerides, are difficult to nanoemulsify. Alternatively, oils with medium-chain triglycerides and short-chain fatty acids; suchas, medium-chain monoglycerides and fatty acid esters, e.g., ethyl oleate are easy to nanoemulsify ${ }^{26,28}$. Modified or hydrolyzed vegetable oils have been widely used because of the high drug solubility and good emulsification properties that are compatible with a large number of surfactants approved for oral administration. Semisynthetic medium-chain derivatives; such as, medium-chain triglycerides, e.g., caprylic/capric triglyceride, Miglyol ${ }^{\circledR}$ 812, and Captex ${ }^{\circledR} 355$ have also been highly developed. According to their structure as amphiphilic compounds with surfactant properties, they are of interest and effectively replacing the regular medium-chain triglycerides ${ }^{29,30}$. Furthermore, the degraded products of these oils resemble the natural end products of intestinal digestion. In some cases, to achieve the optimal nanoemulsification and drug delivery, the use of oil mixture is acceptable to meet the optimal property of the oily phase. For example, as shown in the study of Jumaa et al. ${ }^{31}$, a mixture of fixed oil and a mediumchain triglyceride provided an appropriate balance between the drug loading and emulsification. Several oil components employed in the preparation of the SNEDDS for oral delivery are listed in Table 1. 
Table 1. Commonly employed oil components in the preparation of SNEDDS for oral delivery

\begin{tabular}{lll}
\hline \multicolumn{1}{c}{ General class } & \multicolumn{1}{c}{ Examples } & \multicolumn{1}{c}{ Commercial name } \\
\hline Fixed oils & Castor oil, Soybean oil & - \\
Medium chain triglycerides & Tryglycerides of capric/caprylic acids & Miglyol 812, Labrafac CC, \\
& & Crodamol GTCC
\end{tabular}

\begin{tabular}{lll}
\hline $\begin{array}{l}\text { Medium chain mono- and } \\
\text { diglycerides }\end{array}$ & $\begin{array}{l}\text { Mono- and diglycerides of } \\
\text { capric/caprylic acids }\end{array}$ & Imwitor 742, Capmul MCM \\
\hline Long chain monoglycerides & Glyceryl momooleate & Peceol, Capmul GMO \\
\hline Propylene glycol fatty acid esters & Propylene glycol monocaprylate & Capryol 90, Capmul PG-8 \\
& Propylene glycol dicaprylate/caprate & Miglyol 840, Captex 200 \\
\hline Fatty acid esters & Ethyl oleate & Crodamol EO \\
\hline Fatty acids & Oleic acid & Crossential O94 \\
& Caprylic acid & - \\
\hline Vitamins & Vitamin E & - \\
\hline
\end{tabular}

\subsection{Surfactants}

The properties of the surfactants including the hydrophilic-lipophilic balance (HLB), viscosity, affinity for the oily phase, and concentration of the surfactants influence the self-nanoemulsification process and droplet size of the nanoemulsions ${ }^{28,32-34}$. The surfactants are usually classified as anionic, cationic, and non-ionic. The non-ionic surfactants with high HLB values are commonly used in the preparation of the SNEDDS according to their less toxic properties compared with ionic surfactants. Many non-ionic surfactants have the ability to enhance the permeability and uptake of drugs via P-glycoprotein mediated efflux; such as; Cremophor EL ${ }^{35,36}$. Although, surfactants may cause irritation to the gastrointestinal mucosa, the association of the surfactant with the oil phase like the emulsion form could reduce the unfavorable adverse effect of the surfactant. Exemplifying from the study of Jumaa et al., the hemolytic ability of sodium oleate surfactant was reduced when it was associated in the dispersion of Cremophor EL, Solutol H16, and phospholipid, which was built as a micellar or liposomal structure ${ }^{37}$. Hence, the selection of the appropriate type of surfactants is crucial for the preparation of the SNEDDS. Additionally, the concentration of the selected surfactants should be as low as possible to limit the adverse effect caused by the surfactants. Several surfactants can be chosen either alone or in combination to prepare the SNEDDS with the desirable characteristics for oral delivery (Table 2). 
Table 2. Commonly employed surfactants in the preparation of SNEDDS for oral delivery

\begin{tabular}{lll}
\hline \multicolumn{1}{c}{ General class } & \multicolumn{1}{c}{ Examples } & \multicolumn{1}{c}{ Commercial name } \\
\hline Sorbitan esters & Sorbitan monooleate & Span 80 \\
& Sorbitan monolaurate & Span 20 \\
\hline Polysorbates & Polyoxyethylene-20-sorbitan monooleate & Tween 80 \\
& Polyoxyethylene-20-sorbitan monolaurate & Tween 20 \\
\hline PEO-PPO-block copolymers & Poloxamer 188 & Pluronic F68 \\
& Poloxamer 407 & Pluronic F127 \\
\hline Polyoxyethylene castor oil & Polyoxyethylene 35 castor oil & Cremophor EL \\
\hline Polyoxyethylene & Polyoxyethylene 40 hydrogenated castor oil & Cremophor RH40, HCO-40 \\
hydrogenated castor oil & Polyoxyethylene 60 hydrogenated castor oil & Cremophor RH60, HCO-60 \\
\hline Polyglycolyzed glycerides & Oleoyl macrogol glycerides & Labrafil 1944 CS \\
& Caprylocaproyl macrogol glycerides & Labrasol \\
\hline Polyoxyethylene stearate & Polyethylene glycol-660-12-hydroxysterate & Solutol HS 15 \\
\hline Polyoxyethylene vitamin E & Tocopheryl PEG 1000 succinate & Vitamin E TPGS \\
\hline
\end{tabular}

\subsection{Co-surfactants, and solubilizers}

Co-surfactants and solubilizers are incorporated in the SNEDDS for the purpose of increasing the drug loading to the SNEDDS, improving the self-emulsification time, and modulating the droplet size of the nanoemulsions ${ }^{14,38}$. The use of co-surfactants and solubilizers in the SNEDDS could result in an expanded selfnanoemulsification region in the phase diagram. Co-surfactants and solubilizers that are mostly employed in the preparation of the SNEDDS include propylene glycol, polyethylene glycol, polyoxyethylene, Lauroglycol $^{\mathrm{TM}}$, Transcutol ${ }^{\circledR}$, etc.

\subsection{Drug candidate}

SNEDDS offer the potential to improve the oral bioavailability of drugs, preferentially those in BCS classes II and IV. The drug candidate should be a poorly water soluble drug with an intermediate partition coefficient (log P between 2-4). The physicochemical properties; such as, $\log \mathrm{P}$, $\mathrm{pKa}$, molecular weight, ionization group, and also the amount of drugs have an influence on the performance of the prepared SNEDDS including the phase behavior and final droplet size $\mathrm{e}^{32,34,39}$. It has been further accepted that the drug candidate with a low melting point and low dose would be generally suitable for the preparation of the $\operatorname{SNEDDS}^{40}$.

\subsection{Aqueous phase}

The properties of the aqueous phase where the SNEDDS are administered would affect the droplet size and stability of the nanoemulsions. Therefore, the $\mathrm{pH}$ and ionic content of the aqueous phase should be taken into consideration during the preparation of the SNEDDS ${ }^{32,41}$. The selfnanoemulsification property and characteristic of the obtained nanoemulsions of the SNEDDS in different $\mathrm{pH}$ and electrolyte concentrations of the aqueous phases should be evaluated in accordance with their route of administration.

\section{Construction of the ternary phase diagram}

After the selection of the appropriate excipients for the formulation of the SNEDDS, to identify the probable concentration of the components that could yield spontaneous nanoemulsions, the ternary phase diagram between the surfactant, oil, and solubilizer have to be plotted to identify the self-emulsification region. The self-nanoemulsification region in the ternary phase diagram is evaluated by measuring the droplet size of the emulsions or 
nanoemulsions after diluting the various compositions of the ternary phase diagram with the fixed amount of water. The points that provide the spontaneous nanoemulsions and the droplet size less than 200 $\mathrm{nm}$ indicate the self-nanoemulsification region. The ternary phase diagram is a three-dimensional plot but is displayed in a two-dimensional plot for uncomplicated illustration and interpretation. In the ternary phase diagram, the relative percentage of the three components is plotted to show that all three components have a total of $100 \%$ or are normalized to $100 \%$ (Figure 1).

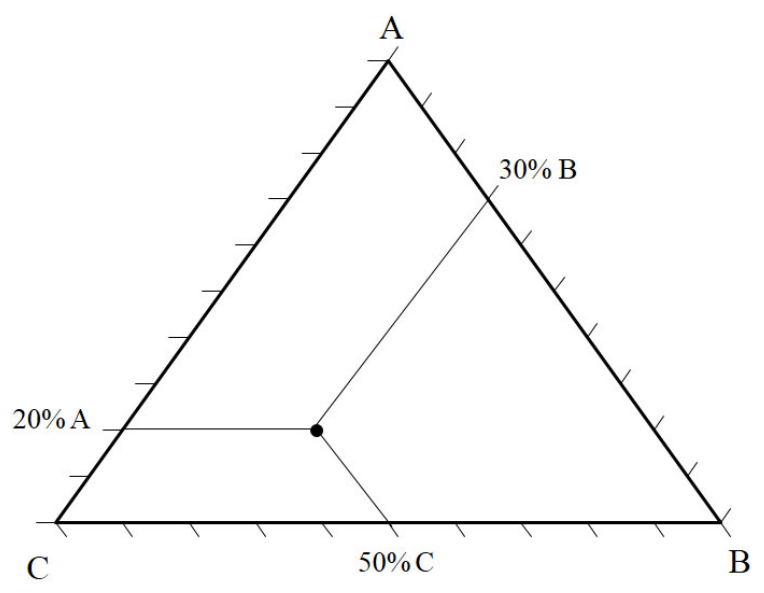

Figure 1. Ternary phase diagram in two-dimensional plot (A, B, C illustrate three components of SNEDDS including oil, surfactant, and co-surfactant)

The optimization of the SNEDDS can also be accomplished using a statistical experimental design or response surface methodology by studying the effect of the numerous variables on the characteristics of the SNEDDS; such as, droplet size, self-nanoemulsification time, and in vitro dissolution. Once the mathematical correlation is found between the variables and the response, the response surface methodology can be used to develop the desired product that has a small droplet size, reduced self-emulsification time, and high in vitro dissolution rate.

\section{Preparation of solid SNEDDS (s-SNEDDS)}

The conventional liquid form of the SNEDDS may result in some restrictions involving the interaction, stability, manufacturing, and convenience of use. Therefore, solid SNEDDS (s-SNEDDS) have been developed to solve these problems of the conventional liquid form. The advantages of s-SNEDDS include increased solubility and bioavailability, enhanced stability, scalability and ability to be manufactured, reproducibility, and robustness ${ }^{42,43}$. Various techniques are employed to solidify or convert the conventional liquid SNEDDS into solid SNEDDS. The frequently used technique is the adsorption on carriers. The free-flowing powders containing the SNEDDS were prepared by adsorption of liquid SNEDDS on the porous powder material, which had a high surface area and oil adsorption capacity. This s-SNEDDS powder could either be loaded in a hard gelatin capsule or compressed into a tablet. The carrier materials used for the adsorption of the SNEDDS are usually microporous inorganic substances, high surface area colloidal inorganic adsorbent substances, cross-linked polymers, or nanoparticle adsorbents; such as, silicate, magnesium trisilicate, magnesium aluminometasilicate $\left(\right.$ Neusilin $\left.^{\circledR}\right)$, talcum, cross-povidone, cross-linked sodium carboxymethylcellulose, and cross-linked polymethyl methacrylate ${ }^{44-46}$. The alternative of the adsorption for solidification is the use of emulsifiers that are themselves solid or semisolid. The commonly used solid amphiphiles include Soluplus and Cithrol GSM 40, and the semisolid amphiphiles are those like Cithrol dipoly hydroxy stearate (DPHS) and Kolliphor HS 15 ${ }^{47,48}$. For the selection of solid or semisolid amphiphiles, their 
characteristics should be examined; such as, the melting point, solubility of the drug, HLB, dispersibility, and droplet size in different media that may affect the properties of the obtained s-SNEDDS ${ }^{46,48}$. Other techniques could also be employed in the solidification of the SNEDDS; such as, spray-drying, freeze-drying, melt granulation, and melt extrusion/extrusion spheronization ${ }^{49}$. The chosen method should depend on the physicochemical properties of the excipients and the designed properties of the powder.

\section{Characterization of the SNEDDS ${ }^{13,50,51}$}

The final SNEDDS should be characterized for various parameters including:

\subsection{Droplet size and polydispersity index}

The droplet size (z-ave) and polydispersity index (PI value) can be determined by using a photon correlation spectroscopy technique. The sample should be dispersed in a suitable solvent to an appropriate concentration, and mixing would be required in the preparation of the sample.

\subsection{Zeta potential}

The particle charge of formed nanoemulsions can be determined according to the Smoluchowski theory. Zeta potential indicates the stability of the colloidal dispersion. The formulation would remain stable if it has a high zeta potential, especially when the zeta potential value is more than $\pm 30 \mathrm{mV}$.

\subsection{Morphology}

The morphology of the nanoemulsion droplets can be determined by transmission electron microscopy (TEM) and scanning electron microscopy (SEM). The TEM technique would provide the information on the inner structure of the vesicles whereas the SEM technique would provide the surface morphology of the vesicles. The sample might be diluted to a suitable concentration before the measurement.

\subsection{Self-nanoemulsification time}

The efficiency of self-nanoemulsification is assessed using a dissolution apparatus. In general,
$1 \mathrm{~mL}$ of the SNEDDS is dissolved in $250 \mathrm{~mL}$ of water at $37 \pm 0.5^{\circ} \mathrm{C}$. Gentle agitation is applied by paddle rotating at $50 \mathrm{rpm}$. SNEDDS are assessed visually according to the rate of emulsification and the final appearance of the emulsion. The time taken for the emulsification is noted. On completion of the emulsification, the samples are taken for particle sizing by photon correlation spectroscopy and further processing by other characterizations.

\subsection{Refractive index}

The refractive index (RI) is used as an important tool to investigate the presence of transparent formulation. The RI of the system is measured using a refractometer by placing a drop of the solution on a slide and comparing with water, which has an RI of 1.333. If the RI of the system is similar to the RI of water, the formulation has a transparent nature. The RI is also employed for determining the thermodynamic stability of the formulation. The insignificant changes in the RI during the different time points of the storage would indicate the constant structure and thermodynamic stability of the SNEDDS.

\subsection{Percentage transmittance}

The percentage transmittance of the system is determined following the dilution of the formulation at $638 \mathrm{~nm}$ wavelength by a UVspectrophotometer and using the water as blank. If the percentage transmittance value is closer to $100 \%$, the formulation would indicate a clear and transparent nature.

\subsection{Viscosity}

The viscosity of liquid SNEDDS is generally determined by a viscometer; such as, Brookfield cone and plate viscometer. The viscosity is presented in terms of centipoises, which is related to the shear rate.

\subsection{In vitro dissolution profile}

The in vitro dissolution profile of the SNEDDS should be evaluated using a dissolution apparatus Type II in various dissolution media associated with the purposed route of administration; such as, $\mathrm{pH} 1.2$ and $\mathrm{pH} 6.8$ for oral application. 
The dissolved drug in the dissolution media would be collected during a set period of time and analyzed by an appropriate analytical method. Cumulative amounts of drug dissolved against the times of the SNEDDS would be plotted compared with the pure drug.

\subsection{Drug loading efficiency}

The percentage of the drug entrapped in the vesicles would be determined by mixing a certain amount of the formulation with a suitable solvent that would break down the vesicles and dissolve the drug for producing a certain volume. The mixture would be stirred on a magnetic stirrer for a suitable period of time. The supernatant would be filtered and analyzed by an appropriate analytical method. The drug loading efficiency can be calculated from Equation 2.

Drug loading efficiency $=[($ Initial drug load - Amount of drug in the filtrate $) /$ Initial drug load $]$ x 100 Eq.2

\subsection{Thermodynamic stability ${ }^{52}$}

In the development process, to overcome the problem of metastable formulation, a thermodynamic stability test would be performed. The liquid SNEDDS would be centrifuged at $3,500 \mathrm{rpm}$ for $30 \mathrm{~min}$. The formulation that does not show any phase separation would be subjected to the heating-cooling cycle. Six cycles between $4^{\circ} \mathrm{C}$ and $45^{\circ} \mathrm{C}$ for $48 \mathrm{~h}$ would be conducted. The formulation that is still stable would then be subjected to the freeze-thaw stress test by achieving three cycles between $-21^{\circ} \mathrm{C}$ and $25^{\circ} \mathrm{C}$ for $48 \mathrm{~h}$. The formulation that survives the thermodynamic stability test would be chosen as the stable formulation for further studies.

\subsection{Stability assessment ${ }^{53}$}

The stability study of nanomedicines including the SNEDDS should be performed following the guidelines of the International Council for Harmonization of Technical Requirements for Pharmaceuticals for Human Use (ICH). For the non-targeted nanomedicines, which are free from the regulations for biotechnological products, these should follow the procedures of the ICH Q1A(R2) and Q1C guidelines. Meanwhile, the targeted nanomedicines, which are mostly incorporated with biotechnological products, should follow the procedures of the ICH Q5C guideline.

SNEDDS should also be evaluated under the storage conditions for their thermal stability and sensitivity to moisture. In general, the recommended long-term and accelerated storage conditions by the $\mathrm{ICH}$ guidelines are $25^{\circ} \mathrm{C} \pm 2{ }^{\circ} \mathrm{C} / 60 \% \mathrm{RH} \pm$ $5 \% \mathrm{RH}$ and $40^{\circ} \mathrm{C} \pm 2{ }^{\circ} \mathrm{C} / 75 \% \mathrm{RH} \pm 5 \% \mathrm{RH}$, respectively. Appropriately, an intermediate storage condition $\left(30^{\circ} \mathrm{C} \pm 2{ }^{\circ} \mathrm{C} / 65 \% \mathrm{RH} \pm 5 \% \mathrm{RH}\right)$ is recommended. In addition, if any drug products are intended for storage in a refrigerator, long-term and accelerated storage conditions are recommended at $5^{\circ} \mathrm{C} \pm 3{ }^{\circ} \mathrm{C}$ and $25^{\circ} \mathrm{C} \pm 2{ }^{\circ} \mathrm{C} / 60 \% \mathrm{RH} \pm 5 \% \mathrm{RH}$, respectively. The samples should be characterized by their properties; such as, appearance, color, drug content, and dissolution profile. If these properties match the initial formulation, it can be concluded as a stable formulation.

Additionally, the s-SNEDDS can be characterized by further parameters; such as, micromeritic properties including bulk density, tapped density, angle of repose, etc. The drug content in the s-SNEDDS should be evaluated by dissolving the s-SNEDDS in a suitable solvent and analyzing the drug content in the solvent extract using an appropriate analytical method. Other parameters associated with the prepared tablets from the s-SNEDDS might be evaluated including hardness, friability, weight variation, disintegration, and dissolution.

\section{Potential effects of the SNEDDS on oral drug delivery}

\subsection{Improve the dissolution rate-limited absorption}

Therapeutic agents with poor solubility in water; such as, drugs in the BCS classes II and IV usually have limited absorption in the gastrointestinal tract according to their poor dissolution rate. The compositions used in the preparation of the SNEDDS provide high solubilization potential for various hydrophobic drugs. Thus, a drug solubilized in the SNEDDS should produce a higher dissolution rate as compared to a pure drug. Furthermore, SNEDDS usually provide 
very fine nanoemulsions after being presented in the gastrointestinal fluid. These very small droplets have a high surface area for absorption resulting in the quick absorption and the improvement of oral bioavailability.

\subsection{Improve the permeability of poorly permeable drugs}

Therapeutic agents in the BCS class III have limited oral bioavailability according to their poor permeability property. Various compositions in the SNEDDS including oily phases, surfactants, and co-surfactants are known to help in the enhancing of the membrane permeability, subsequently providing the ability of the SNEDDS to improve the permeability and oral bioavailability of drugs.

\subsection{Reduce the first pass metabolism or presystemic metabolism of the drugs}

Various compositions of the SNEDDS have the potential to inhibit the activity of cytochrome P450 and gut metabolism enzymes. These compositions include Gelucire ${ }^{\circledR}$ 44/14 (lauroyl macrogol glycerides) and Labrasol ${ }^{\circledR}$ (caprylo-caproyl macrogol glycerides) $)^{7,8,36}$. Additionally, some lipid compositions including long-chain tri- and mono- glycerides, i.e., glyceryl monooleate have the potential to stimulate the intestinal lymphatic transport of hydrophobic drugs ${ }^{54}$. These two mechanisms are consequently associated with the reduction in the first pass metabolism of the drugs leading to an increase in oral bioavailability ${ }^{55}$.

\subsection{Inhibit P-glycoprotein efflux}

Some compositions of the SNEDDS including lipids; such as, Peceol ${ }^{\circledR}$ (glyceryl monooleate), Imwitor ${ }^{\circledR} 742$ (monoglyceride of caprylic acid), and Akoline $\mathrm{MCM}^{\circledR}$ (diglyceride of caprylic acid), and surfactants; such as, Gelucire ${ }^{\circledR}$ 44/14, Labrasol, Cremophor EL, and polysorbate 80 have the ability to inhibit the activity of a Pglycoprotein efflux pump, which is the intestinal efflux transporter. The entry of drugs from the gastrointestinal tract to the systemic circulation would be increased; thus, the bioavailability of drugs would be improved.

\subsection{Change in the pharmacokinetic parameters}

The improvement in oral absorption of the SNEEDS would result in the rapid onset of the action of drugs, which would be very beneficial for many drugs requiring quick action. In the study of Nepal et al..$^{56}$, the pharmacokinetic parameters of coenzyme Q10 SNEDDS were compared with a conventional formulation. The results showed that the $t_{\text {max }}$ of the SNEDDS formulation was $6 \mathrm{~h}$ which was reduced by 2 -fold as compared to the conventional formulation $(12 \mathrm{~h})$ indicating the quick onset of action of the SNEDDS formulation. Furthermore, the ability of the SNEDDS improved the $\mathrm{C}_{\text {max }}$ from $86.6 \mathrm{ng} / \mathrm{mL}$ in a powder formulation to $480 \mathrm{ng} / \mathrm{mL}$ in a SNEDDS formulation, and increased the oral bioavailability (AUC) from $1,110 \mathrm{ngh} / \mathrm{mL}$ in a powder formulation to 5,070 $\mathrm{ngh} / \mathrm{mL}$ in a SNEDDS formulation. The results were related to the improvement in the therapeutic effects. An increment in the bioavailability of a drug might produce a reduction in the drug dosage and dose-related side effects of some drugs.

\subsection{Reduction in food effects}

The fed and fasted states dissolution media do not affect the droplet size of the SNEDDS. Therefore, the SNEDDS formulation could reduce the bioavailability ratio between the fed and fasted states and the reproducibility of the plasma profile of the drugs in fed and fasted conditions could be obtained. As demonstrated by Nielsen et al..$^{57}$, the bioavailability of probucol in minipigs showed that the probucol SNEDDS were not affected by the fed and fasted states. Alternatively, the variation in the fed and fasted states bioavailability was significantly observed in the probucol powder formulation.

\subsection{Enhance mucus permeation}

The mucus layer is the barrier for drug permeation through the mucosa. Mucus is composed of glycoproteins called mucins which are negatively charged at a physiological $\mathrm{pH}$. The rapid mucus secretion and faster clearance rate of the mucus are the challenging barriers of the drug delivery systems to reach the epithelial surface and remain there for a sufficient period of time. SNEEDS are the promising technology 
for mucus permeation. The interaction between self-emulsified nanoemulsions and the mucus is low because of their hydrophobic surface that can cross the mucus layer without being entrapped. The very small vesicle size and shape deforming potential of self-emulsified nanoemulsions help the SNEDDS to permeate through the mucus layer ${ }^{58,59}$. The modification of the SNEDDS surface with positively or negatively charged surfactants could also result in the enhancement of mucus permeability. Additionally, a mucoadhesive polymer; such as, HPMC could be used by covering the droplet surface of the SNEDDS and binding SNEDDS to the mucus, which would lead to prolonging the residence time for permeation ${ }^{58}$.

\subsection{Improve the oral delivery of bio-macro molecules}

Bio-macromolecules include lipids, proteins, genes, and polysaccharides. These macromolecules usually have low bioavailability, as a result of poor permeation according to the large size and hydrophilicity of actives (proteins), and the poor stability due to the enzymatic degradation in the gastrointestinal environment ${ }^{60}$. These problems are significant challenges for drug delivery. SNEDDS also have the ability to improve drug solubilization, increase the droplet surface area, protect drugs from enzymatic degradation, modify the gastrointestinal tract retention time, and enhance permeation. Additionally, SNEDDS can incorporate a hydrophilic drug in oil droplets through slight modifications. For example, using the combined technology of a polymer and SNEDDS, insulin was incorporated into the SNEDDS in the presence of thiolated chitosan, which was successful for oral insulin administration ${ }^{61}$. Solid dispersion is one technique that hydrophilic proteins can be initially dissolved or adsorbed in phospholipids and subsequently dissolved in oil to form the SNEDDS ${ }^{62}$. Another interesting technique is hydrophobic ion pairing by replacing the counter ions of peptide drugs with groups inducing lipophilicity without altering the structure of the drugs as observed in the study of Karamanidou et al. ${ }^{63}$. From having an acidic $\mathrm{pH}$, insulin showed the net positive charge and could undergo ion complexation with the anionic part of the amphiphilic molecules; such as, surfactants, fatty acids, and phospholipids in order to be incorporated in the SNEDDS. The hydrophobic ion pair of insulin and dimyristoylphosphatidylglycerol (DMPG) was developed and incorporated into the SNEDDS. The insulin/DMPG SNEDDS exhibited increased mucus permeability and a decreased enzymatic degradation of insulin. Furthermore, there were several studies presenting the successful development of SNEDDS loaded with pDNA and proteins that could increase permeation and reduce the enzymatic degradation of actives in the gastrointestinal tract; such as, insulin and

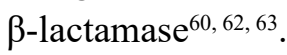

\section{SNEDDS formulations in the market ${ }^{51}$}

There are several drugs that have been developed as SNEDDS. Some drugs are still in the researching process, and some have enough potential to be launched as marketed products. The exemplification of the marketed formulations of the SNEDDS are shown in Table 3.

Table 3. Commercial available products of SNEDDS

\begin{tabular}{cllcll}
\hline Drug & Trade name & Manufacturer & BCS class & Dosage form & \multicolumn{1}{c}{ Ingredient } \\
\hline Cyclosporine & Sandimmune ${ }^{\circledR}$ & Novartis & IV & $\begin{array}{l}\text { Soft gelatin } \\
\text { capsules }\end{array}$ & $\begin{array}{l}\text { Corn oil, linoleoylmacrogol } \\
\text { glycerides, sorbitol }\end{array}$ \\
\hline Cyclosporine & Neoral ${ }^{8}$ & Novartis & IV & $\begin{array}{l}\text { Soft gelatin } \\
\text { capsules }\end{array}$ & $\begin{array}{l}\text { Corn oil-mono-di- } \\
\text { triglycerides, } \\
\text { polyoxyethylene } 40 \\
\end{array}$ \\
& & & & hydrogenated castor oil, \\
& & & & DL- $\alpha$-tocopherol \\
\hline
\end{tabular}




\begin{tabular}{|c|c|c|c|c|c|}
\hline Drug & Trade name & Manufacturer $\mathrm{BC}$ & 3CS class & Dosage form & Ingredient \\
\hline Cyclosporine & Gengraf $\AA$ & AbbVie & IV & $\begin{array}{l}\text { Hard gelatin } \\
\text { capsules }\end{array}$ & $\begin{array}{l}\text { Polyethylene glycol, } \\
\text { polyoxyethylene } 35 \text { castor } \\
\text { oil, polysorbate } 80 \text {, propylene } \\
\text { glycol, sorbitan monooleate, } \\
\text { titanium dioxide }\end{array}$ \\
\hline Ritonavir & Norvir $\circledast$ & AbbVie & II & $\begin{array}{l}\text { Soft gelatin } \\
\text { capsules }\end{array}$ & $\begin{array}{l}\text { Butylated hydroxytoluene, } \\
\text { ethanol, oleic acid, } \\
\text { polyoxyethylene } 35 \text { castor } \\
\text { oil }\end{array}$ \\
\hline Saquinavir & Fortovase $\AA$ & Roche & IV & $\begin{array}{l}\text { Soft gelatin } \\
\text { capsules }\end{array}$ & $\begin{array}{l}\text { Medium chain mono- and } \\
\text { diglycerides, povidone, } \\
\text { DL- } \alpha \text {-tocopherol }\end{array}$ \\
\hline Amprenavir & Agenerase $\AA$ & GlaxoSmithKline & he II & $\begin{array}{l}\text { Soft gelatin } \\
\text { capsules }\end{array}$ & $\begin{array}{l}\text { D- } \alpha \text {-tocopheryl PEG } 1000 \\
\text { succinate (TPGS), PEG 400, } \\
\text { propylene glycol }\end{array}$ \\
\hline Tipranavir & Aptivus $\AA$ & $\begin{array}{l}\text { Boehringer } \\
\text { Ingelheim }\end{array}$ & II & $\begin{array}{l}\text { Soft gelatin } \\
\text { capsules }\end{array}$ & $\begin{array}{l}\text { Dehydrated alcohol, } \\
\text { polyoxyethylene } 35 \text { castor } \\
\text { oil, propylene glycol, mono/ } \\
\text { diglycerides of caprylic/ } \\
\text { capric acid } \\
\end{array}$ \\
\hline Bexarotene & Targretin $®$ & $\begin{array}{l}\text { Ligand } \\
\text { Pharmaceuticals }\end{array}$ & II & $\begin{array}{l}\text { Soft gelatin } \\
\text { capsules }\end{array}$ & $\begin{array}{l}\text { Polyethylene glycol } 400, \\
\text { polysorbate } 20, \text { povidone, } \\
\text { butylated hydroxyanisole }\end{array}$ \\
\hline$\overline{\text { Calcitriol }}$ & Rocaltrol® & Roche & II & $\begin{array}{l}\text { Soft gelatin } \\
\text { capsules }\end{array}$ & Triglyceride of coconut oil \\
\hline
\end{tabular}

10. Advanced technology and trend of the SNEDDS

\subsection{Supersaturated SNEDDS}

The reduction in the lipid content of the SNEDDS has resulted in the declining in vivo solubilizing capacity of the SNEDDS. Therefore, the drugs precipitate. Drugs which are more soluble in the surfactant than the lipid phase are at risk of precipitation because of a decrease in the solvent capacity of the surfactant upon dilution. For this reason, SNEDDS usually contain drug less than the equilibrium solubility. The supersaturated SNEDDS containing hydrophilic precipitation inhibitors have been developed to resolve this limitation. The hydrophilic precipitation inhibitor in supersaturated SNEDDS inhibits the nucleation process and subsequent drug precipitation in the gastrointestinal tract by achieving and sustaining a metastable supersaturated state ${ }^{64}$. The polymeric precipitation inhibitors that are commonly incorporated in the SNEDDS include polyvinyl pyrrolidone, methyl cellulose, sodium carboxymethyl cellulose, and hydroxypropyl methyl cellulose ${ }^{64,65}$. Supersaturated SNEDDS could improve the stability, dissolution rate, and bioavailability of drugs in many studies; such as, simvastatin ${ }^{66}$, silybin ${ }^{65}$, paclitaxel $^{67}$, and hydrocortisone ${ }^{68}$. 
10.2 Self-double nanoemulsifying drug delivery systems (SDEDDS)

Proteinsandhydrophilicmacromolecules are usually difficult to be administered orally in the form of SNEDDS. Therefore, SDEDDS are a promising technology that could resolve this problem. SDEDDS are w/o/w spontaneous emulsions that consist of hydrophilic surfactant and w/o emulsions where the $\mathrm{w} / \mathrm{o} / \mathrm{w}$ emulsions were spontaneously formed during dilution with water at mild agitation. SDEDDS are applicable for peptides, proteins, and other macromolecular drugs; such as, insulin and nattokinase. They can protect these macromolecules from enzymatic degradation in the gastrointestinal tract and improve drug efficacy ${ }^{69,70}$.

\subsection{Controlled release SNEDDS}

SNEDDS can be employed as extended release delivery systems for poorly water soluble drugs. Various techniques used for controlled release SNEDDS include microencapsulation, polymer coating, sustained release pellets, and controlled release osmotic pump. Different polymers are used in the preparation of controlled release SNEDDS; such as, microcrystalline cellulose, hydroxypropyl methyl cellulose (HPMC), poly lactic glycolic acid (PLGA), and Gelucire ${ }^{\circledR 71-73}$. From the study of Patil et al., an extended release was observed from felodipine SNEDDS developed using Aerosil 200 as the gelling agent, and the gelled SNEDDS were then entrapped in Gelucire ${ }^{\circledR}$ $43 / 01^{74}$.

\subsection{Targeted SNEDDS}

SNEDDS have the ability to be a targeted drug delivery by surface functionalization. Nanoemulsion droplets have the ability to be maintained in the circulation for a long duration of time. Cationic nanoemulsions can also directly attach to the anionic membrane barriers ${ }^{75}$. The lipid-based SNEDDS can be accepted by the liver and spleen, which is the simplest way for targeting these organs ${ }^{76}$. Moreover, SNEDDS are preferentially useful for a drug targeting lymphatic system and also have the opportunity for targeting macrophages ${ }^{77}$. The surface tailor of the SNEDDS for stealth properties can be achieved by linking with hydrophilic polymers; such as, PEGylation by polyethylene glycol $^{78}$. Active and passive targeting can be attained by attaching appropriate ligands; such as, antibodies and peptides of the target receptors ${ }^{79}$.

\section{CONCLUSIONS}

SNEDDS offer an enhancement of absorption and dissolution rate for poorly water soluble drugs, where the absorption is limited due to the rate of dissolution. Consequently, an improvement in oral bioavailability could be obtained. The techniques and additives used to formulate SNEDDS are economic and simple. The ease of manufacturing and good physical stability has resulted in SNEDDS to be of interest in several areas of research and successful in many commercial products. As a future perspective, advances in lipid and surfactant technology and the modification of SNEDDS with other technologies; such as, polymer sciences and biological targeting could result in SNEDDS to be applicable and provide valuable advantages to pharmaceutical research.

\section{ACKNOWLEDGEMENT}

This research project was supported by Mahidol University, Bangkok, Thailand.

\section{Conflict of interest (If any)}

None to declared

\section{Funding}

None to declared

\section{Ethical approval}

None to declared

\section{Article info:}

Received November 6, 2019

Received in revised form March 10, 2020

Accepted March 30, 2020

\section{REFERENCES}

1. Lipinski C. Poor Aqueous Solubility - an Industry Wide Problem in Drug Discovery. Am Pharm Rev. 2002;5(3):82-5.

2. Cerpnjak K, Zvonar A, Gasperlin M, Vrecer F. Lipid-based Systems as a Promising Approach for Enhancing the Bioavailability of Poorly Water-soluble Drugs. Acta pharm. 2013;63 (4):427-45. 
3. Pouton CW. Lipid Formulations for Oral Administration of drugs: Non-emulsifying, Self-emulsifying and 'self-microemulsifying' Drug Delivery Systems. Eur J Pharm Sci. 2000;11 Suppl 2:S93-8.

4. Brusewitz C, Schendler A, Funke A, Wagner T, Lipp R. Novel Poloxamer-based Nanoemulsions to Enhance the Intestinal Absorption of Active Compounds. Int J Pharm. 2007;329(1-2): 173-81.

5. Seeballuck F, Lawless E, Ashford MB, O'Driscoll CM. Stimulation of Triglyceride-rich Lipoprotein Secretion by Polysorbate 80: in vitro and in vivo Correlation using Caco-2 Cells and a Cannulated Rat Intestinal Lymphatic Model. Pharm Res. 2004;21(12):2320-6.

6. Mohsin K SA, Alanazi F. Lipid based self emulsifying formulations for Poorly Water Soluble Drugs-an Excellent Opportunity. Indian J Pharm Educ Res. 2012;46:88-196.

7. Subramanian R, Wasan KM. Effect of Lipid Excipients on in vitro Pancreatic Lipase Activity. Drug Dev Ind Pharm. 2003;29(8): 885-90.

8. Ren S, Park MJ, Kim A, Lee BJ. In Vitro Metabolic Stability of Moisture-sensitive Rabeprazole in Human Liver Microsomes and Its Modulation by Pharmaceutical Excipients. Arch Pharm Res. 2008;31(3):406-13.

9. Vemula RB. Lipid based Self-emulsifying Drug Delivery System (SEDDS) for Poorly Water-Soluble Drugs: a Review. J Global Pharma Technol. 2010;2(3):47-55.

10. Puri A, Loomis K, Smith B, Lee JH, Yavlovich A, Heldman E, et al. Lipid-based Nanoparticles as Pharmaceutical Drug Carriers: From Concepts to Clinic. CritRevTherDrug. 2009;26(6):52380.

11. Alonso MJ. Nanomedicines for Overcoming Biological Barriers. Biomed Pharmacother. 2004;58(3):168-72.

12. Bates TR, Carrigan PJ. Apparent Absorption Kinetics of Micronized Griseofulvin After its Oral Administration on Single- and Multipledose Regimens to Rats as a Corn Oil-in-water Emulsion and Aqueous Suspension. J Pharm Sci. 1975;64(9):1475-81.

13. Date AA, Desai N, Dixit R, Nagarsenker M. Self-Nanoemulsifying Drug Delivery Systems:
Formulation Insights, Applications and Advances. Nanomedicine. 2010;5(10):1595-616. 14. Singh B, Bandopadhyay S, Kapil R, Singh R, Katare O. Self-emulsifying Drug Delivery Systems (SEDDS): Formulation Development, Characterization, and Applications. Crit Rev Ther Drug. 2009;26(5):427-521.

15. Nanjwade BK, Patel DJ, Udhani RA, Manvi FV. Functions of Lipids for Enhancement of Oral Bioavailability of Poorly Water-soluble Drugs. Sci Pharm. 2011;79(4):705-27.

16. Shakeel F, Iqbal M, Ezzeldin E. Bioavailability Enhancement and Pharmacokinetic Profile of an Anticancer Drug Ibrutinib by Selfnanoemulsifying Drug Delivery System. J Pharm Pharmacol. 2016;68(6):772-80.

17. Khan AW, Kotta S, Ansari SH, Sharma RK, Ali J. Potentials and Challenges in Selfnanoemulsifying Drug Delivery Systems. Expert Opin Drug Deliv. 2012;9(10):1305-17.

18. Gupta S, Chavhan S, Sawant KK. Selfnanoemulsifying Drug Delivery System for Adefovir dipivoxil: Design, Characterization, In Vitro and Ex Vivo Evaluation. Colloid Surface A. 2011;392(1):145-55.

19. Cherniakov I, Domb AJ, Hoffman A. Selfnano-emulsifying Drug Delivery Systems: an Update of the Biopharmaceutical Aspects. Expert Opin Drug Deliv. 2015;12(7):1121-33.

20. Chime S, Kenechukwu F, Attama A. Nanoemulsions - Advances in Formulation, Characterization and Applications in Drug Delivery. In: Sezer A, editor. Application of Nanotechnology in Drug Delivery. Croatia: IntechOpen; 2014. p. 77-126.

21. Larsen AT, Ohlsson AG, Polentarutti B, Barker RA, Phillips AR, Abu-Rmaileh R, et al. Oral Bioavailability of Cinnarizine in Dogs: Relation to SNEDDS Droplet Size, Drug Solubility and In Vitro Precipitation. Eur J Pharm Sci. 2013;48(1-2):339-50.

22. Patel A, Shelat P, Lalwani A. Development and Optimization of Solid Self-nanoemulsifying Drug Delivery System (S-SNEDDS) using Scheffe's Design for Improvement of Oral Bioavailability of Nelfinavir Mesylate. Drug Deliv Transl Res. 2014;4(2):171-86.

23. Reiss H. Entropy-induced Dispersion of Bulk Liquids. J Colloid Interf Sci. 1975;53(1):61-70. 
24. Wakerly MG, Pouton CW, Meakin BJ, Morton FS. Self-Emulsification of Vegetable OilNonionic Surfactant Mixtures. Phenomena in Mixed Surfactant Systems. ACS Symposium Series. 311: American Chemical Society; 1986. p. 242-55.

25. Bouchemal K, Briancon S, Perrier E, Fessi H. Nano-emulsion Formulation using Spontaneous Emulsification: Solvent, Oil and Surfactant Optimisation. Int J Pharm. 2004;280(1-2): 241-51.

26. Anton N, Vandamme TF. The Universality of Low-energy Nano-emulsification. Int J Pharm. 2009;377(1-2):142-7.

27. Pouton CW, Porter CJ. Formulation of Lipidbased Delivery Systems for Oral Administration: Materials, Methods and Strategies. Adv Drug Deliv Rev. 2008;60(6):625-37.

28. Sadurní N, Solans C, Azemar N, García-Celma MJ. Studies on the Formation of O/W Nanoemulsions, by Low-energy Emulsification Methods, Suitable for Pharmaceutical Applications. Eur J Pharm Sci. 2005;26(5):438-45.

29. Patel P, Chaulang G, Akolkotkar A, Mutha S, Hardika S, Bhosale A. Self Emulsifying Drug Delivery System: a Review. Res J Pharm Technol. 2008;1(4):131-23.

30. Dipak KS. Engineering of Nanoemulsions for Drug Delivery. Curr Drug Deliv. 2005;2(4): 297-310.

31. Jumaa M, Muller BW. Formulating and Stability of Benzodiazepines in a New Lipid Emulsion Formulation. Die Pharmazie. 2002; 57(11):740-3.

32. Date AA, Nagarsenker MS. Design and Evaluation of Self-nanoemulsifying Drug Delivery Systems (SNEDDS) for Cefpodoxime Proxetil. Int J Pharm. 2007;329(1-2):166-72.

33. Basalious EB, Shawky N, Badr-Eldin SM. SNEDDS Containing Bioenhancers for Improvement of Dissolution and Oral Absorption of Lacidipine. I: Development and Optimization. Int J Pharm. 2010;391(1-2): 203-11.

34. Wang L, Dong J, Chen J, Eastoe J, Li X. Design and Optimization of a New Self-Nanoemulsifying Drug Delivery System. J Colloid Interface Sci. 2009;330(2):443-8.

35. Rege BD, Kao JPY, Polli JE. Effects of Nonionic
Surfactants on Membrane Transporters in Caco-2 cell Monolayers. Eur J Pharm Sci. 2002;16(4):237-46.

36. Mountfield RJ, Senepin S, Schleimer M, Walter I, Bittner B. Potential Inhibitory Effects of Formulation Ingredients on Intestinal Cytochrome P450. Int J Pharm. 2000;211 (1-2):89-92.

37. Jumaa M, Muller BW. Lipid Emulsions as a Novel System to Reduce the Hemolytic activity of Lytic Agents: Mechanism of the Protective Effect. Eur J Pharm Sci. 2000;9(3):285-90.

38. Biradar SV, Dhumal RS, Paradkar AR. Rheological Investigation of Self-emulsification Process: Effect of Co-surfactant. J Pharm Pharm Sci. 2009;12(2):164-74.

39. Dixit RP, Nagarsenker MS. Formulation and In Vivo Evaluation of Self-nanoemulsifying Granules for Oral delivery of a Combination of Ezetimibe and Simvastatin. Drug Dev Ind Pharm. 2008;34(12):1285-96.

40. Khasia H, VD. K. A Review on Self Emulsifying Drug Delivery System. IJPCS. 2012;1(1):353-9.

41. de Morais JM, dos Santos ODH, Delicato T, da Rocha-Filho PA. Characterization and Evaluation of Electrolyte Influence on Canola Oil/Water Nano-Emulsion. J Disper Sci Technol. 2006;27(7):1009-14.

42. Singh S, Pathak K, Bali V. Product Development Studies on Surface-Adsorbed Nanoemulsion of Olmesartan Medoxomil as a Capsular Dosage Form. AAPS PharmSciTech. 2012;13(4): 1212-21.

43. Kamel AO, Mahmoud AA. Enhancement of Human Oral Bioavailability and In Vitro Antitumor Activity of Rosuvastatin via Spray Dried Self-nanoemulsifying Drug Delivery System. J Biomed Nanotechnol. 2013;9(1): 26-39.

44. Abbaspour M, Jalayer N, Sharif Makhmalzadeh B. Development and Evaluation of a Solid Self-nanoemulsifying Drug Delivery System for Loratadin by Extrusion-spheronization. Adv Pharm Bull. 2014;4(2):113-9.

45. Kallakunta VR, Bandari S, Jukanti R, Veerareddy PR. Oral Self Emulsifying Powder of Lercanidipine Hydrochloride: Formulation and Evaluation. Powder Technol. 2012;221:375-82. 46. Van Speybroeck M, Williams HD, Nguyen 
TH, Anby MU, Porter CJ, Augustijns P. Incomplete Desorption of Liquid Excipients Reduces the In Vitro and In Vivo Performance of Self-emulsifying Drug Delivery Systems Solidified by Adsorption onto an Inorganic Mesoporous Carrier. Mol Pharm. 2012;9(9): 2750-60.

47. Song WH, Park JH, Yeom DW, Ahn BK, Lee $\mathrm{KM}$, Lee SG, et al. Enhanced Dissolution of Celecoxib by Supersaturating Self-emulsifying Drug Delivery System (S-SEDDS) Formulation. Arch Pharm Res. 2013;36(1):69-78.

48. Hassan TH, Metz H, Mader K. Novel Semisolid SNEDDS based on PEG-30-Dipolyhydroxystearate: Development and Characterization. Int J Pharm. 2014;477(1-2):506-18.

49. Tang B, Cheng G, Gu J-C, Xu C-H. Development of Solid Self-emulsifying Drug Delivery Systems: Preparation Techniques and Dosage Forms. Drug Discov Today. 2008;13(13):606-12.

50. Amala FK, Boby JG, Jeny S, Vinod B, Sunil C. A Review on Self Emulsifying Nanoemulsion. J Pharm Res. 2017; 1(4): 1-17.

51. Kovvasu S, Kunamaneni P, Joshi R, Betageri G. Self-emulsifying Drug Delivery Systems and Their Marketed Products: a Review. Asian J Pharm 2019;13(2):73-84.

52. Shafiq-un-Nabi S, Shakeel F, Talegaonkar S, Ali J, Baboota S, Ahuja A, et al. Formulation Development and Optimization using Nanoemulsion Technique: a Technical Note. AAPS PharmSciTech. 2007; 8(2): E1-E6.

53. Muthu MS, Feng S. Pharmaceutical Stability Aspects of Nanomedicines. Nanomedicine. 2009; 4(8): 857-860.

54. Porter CJH, Kaukonen AM, TaillardatBertschinger A, Boyd BJ, O'Connor JM, Edwards GA, et al. Use of In Vitro Lipid Digestion Data to Explain the In Vivo Performance of Triglyceride-based Oral Lipid Formulations of Poorly Water-soluble Drugs: Studies with Halofantrine. J Pharm Sci. 2004; 93(5):1110-21.

55. Mistry R, Sheth N. A Review: Self Emulsifying Drug Delivery System Int J Pharm Pharm Sci. 2011;3(2):23-8.

56. Nepal PR, Han HK, Choi HK. Preparation and In Vitro-In Vivo Evaluation of Witepsol H35 based Self-nanoemulsifying Drug Delivery
Systems (SNEDDS) of Coenzyme Q(10). Eur J Pharm Sci. 2010;39(4):224-32.

57. Nielsen FS, Petersen KB, Mullertz A. Bioavailability of Probucol from Lipid and Surfactant based Formulations in Minipigs: Influence of Droplet Size and Dietary State. Eur J Pharm Biopharm. 2008;69(2):553-62.

58. Dünnhaupt S, Kammona O, Waldner C, Kiparissides C, Bernkop-Schnürch A. Nanocarrier Systems: Strategies to Overcome the Mucus Gel Barrier. Eur J Pharm Biopharm. 2015;96:447-53.

59. Friedl H, Dunnhaupt S, Hintzen F, Waldner C, Parikh S, Pearson JP, et al. Development and Evaluation of a Novel Mucus Diffusion Test System Approved by Self-nanoemulsifying Drug Delivery Systems. J Pharm Sci. 2013; 102(12):4406-13.

60. Hauptstein S, Prufert F, Bernkop-Schnurch A. Self-nanoemulsifying Drug Delivery Systems as Novel Approach for pDNA Drug Delivery. Int J Pharm. 2015;487(1-2):25-31.

61. Sakloetsakun D, Dunnhaupt S, Barthelmes J, Perera G, Bernkop-Schnurch A. Combining Two Technologies: Multifunctional Polymers and Self-nanoemulsifying Drug Delivery System (SNEDDS) for Oral Insulin Administration. Int J Biol Macromol. 2013;61:363-72.

62. Rao SV, Shao J. Self-nanoemulsifying Drug Delivery Systems (SNEDDS) for Oral Delivery of Protein Drugs: I. Formulation Development. Int J Pharm. 2008;362(1-2):2-9.

63. Karamanidou T, Karidi K, Bourganis V, Kontonikola K, Kammona O, Kiparissides C. Effective Incorporation of Insulin in Mucus Permeating Self-nanoemulsifying Drug Delivery Systems. Eur J Pharm Biopharm. 2015;97 (Pt A):223-9.

64. Bandyopadhyay S, Katare OP, Singh B. Development of Optimized Supersaturable Self-Nanoemulsifying Systems of Ezetimibe: Effect of Polymers and Efflux Transporters. Expert Opin Drug Deliv. 2014;11(4):479-92.

65. Wei Y, Ye X, Shang X, Peng X, Bao Q, Liu M, et al. Enhanced Oral Bioavailability of Silybin by a Supersaturatable Self-emulsifying Drug Delivery System (S-SEDDS). Colloid Surface A. 2012;396:22-8. 
66. Thomas N, Holm R, Garmer M, Karlsson JJ, Mullertz A, Rades T. Supersaturated Selfnanoemulsifying Drug Delivery Systems (Super-SNEDDS) Enhance the Bioavailability of the Poorly Water-soluble Drug Simvastatin in Dogs. AAPS J. 2013;15(1):219-27.

67. Gao P, Rush BD, Pfund WP, Huang T, Bauer JM, Morozowich W, et al. Development of a Supersaturable SEDDS (S-SEDDS) Formulation of Paclitaxel with Improved Oral Bioavailability. J Pharm Sci. 2003;92(12):2386-98.

68. Raghavan SL, Kiepfer B, Davis AF, Kazarian SG, Hadgraft J. Membrane Transport of Hydrocortisone Acetate from Supersaturated Solutions; the Role of Polymers. Int J Pharm. 2001;221(1-2):95-105.

69. Wang X, Jiang S, Wang X, Liao J, Yin Z. Preparation and Evaluation of Nattokinaseloaded self-double-emulsifying Drug Delivery System. Asian J Pharm Sci. 2015;10(5):386-95.

70. Shima M, Tanaka M, Fujii T, Egawa K, Kimura Y, Adachi S, et al. Oral Administration of Insulin Included in Fine W/O/W Emulsions to Rats. Food Hydrocoll. 2006;20(4):523-31.

71. Miao Y, Chen G, Ren L, Pingkai O. Characterization and Evaluation of Self-nanoemulsifying Sustained-release Pellet Formulation of Ziprasidone with Enhanced Bioavailability and No Food Effect. Drug Deliv. 2016;23(7): 2163-72.

72. Park MJ, Balakrishnan P, Yang SG. Polymeric Nanocapsules with SEDDS oil-core for the Controlled and Enhanced Oral Absorption of
Cyclosporine. Int J Pharm. 2013;441(1-2): 757-64.

73. Yi T, Wan J, Xu H, Yang X. Controlled Poorly Soluble Drug Release from Solid Self-Microemulsifying Formulations with High Viscosity Hydroxypropylmethylcellulose. Eur J Pharm Sci. 2008;34(4-5):274-80.

74. Patil PR, Biradar SV, Paradkar AR. Extended Release Felodipine Self-nanoemulsifying System. AAPS PharmSciTech. 2009;10(2): 515-23.

75. Hormann K, Zimmer A. Drug Delivery and Drug Targeting with Parenteral Lipid Nanoemulsions A Review. J Control Release. 2016;223:85-98.

76. Nikonenko B, Reddy VM, Bogatcheva E, Protopopova M, Einck L, Nacy CA. Therapeutic Efficacy of SQ641-NE Against Mycobacterium Tuberculosis. Antimicrob Agents Chemother. 2014;58(1):587-9.

77. Hunter AC, Elsom J, Wibroe PP, Moghimi SM. Polymeric Particulate Technologies for Oral Drug Delivery and Targeting: a Pathophysiological Perspective. Nanomed-Nanotechnol. 2012;8 Suppl 1:S5-20.

78. Laine AL, Gravier J, Henry M, Sancey L, Bejaud J, Pancani E, et al. Conventional Versus Stealth Lipid Nanoparticles: Formulation and In Vivo Fate Prediction through FRET Monitoring. J Control Release. 2014;188:1-8.

79. Park JH, Saravanakumar G, Kim K, Kwon IC. Targeted Delivery of Low Molecular Drugs using Chitosan and Its Derivatives. Adv Drug Deliv Rev. 2010;62(1):28-41. 